\title{
EN TORNO A LA REINA VICTORIA: VISIBILIDAD Y OCULTAMIENTO EN LA REVISTA SUR
}

\author{
POR \\ MARIANO GARCíA \\ Pontificia Universidad Católica Argentina de Buenos Aires
}

Sur es una monarquía constitucional;

Victoria es la reina que reina pero no gobierna;

Bianco es el primer ministro,

y Murena, el favorito del primer ministro

que es el que verdaderamente gobierna. ${ }^{1}$

Pese al feminismo de Victoria Ocampo, fundadora de esa fecunda y a la vez denostada empresa cultural que fue la revista Sur, y pese a adoptar una perspectiva antifascista tras unos titubeos iniciales, la crítica no ha dejado de señalar que, aun cuando muchos de sus colaboradores en la revista Sur mantuviesen relaciones del mismo sexo, la actitud de Ocampo ante la homosexualidad fue de negación, de silencio o de descalificación.

Ella misma se encargó de explayarse sobre lo que debió sufrir a manos del orden patriarcal de su clase por su condición de mujer: su vocación frustrada como actriz, profesión terminantemente prohibida por su familia, la obligó a desplazarse hacia la literatura, donde también las mismas rígidas coerciones de clase alta le impidieron que desarrollara una obra para la que, según sus razonamientos, habría estado en condiciones de superar a Proust. ${ }^{2}$ Su clase social, con la que nunca se atrevió a romper del todo, le puso un alto precio a esa tácita aceptación: frustró su vocación como

\footnotetext{
1 Palabras atribuidas por Juan José Sebreli (Escritos 437) a los hermanos Estela y Patricio Canto, colaboradores y traductores para Sur. John King (1986: 191) cita una fuente que sólo refiere estas palabras a Patricio Canto.

2 En sus Testimonios: Sexta serie, 1957-1962, Victoria Ocampo sostenía que Proust, medio judío y "medio pelo" (126), no podía hablar más que con ignorancia de una clase a la que no pertenecía, a diferencia de Vita Sackville-West. En una carta a Bianco aplicará el mismo razonamiento respecto de Sebreli (un outsider de clase media que se atrevía a escribir sobre los Anchorena) y ella misma (Sebreli, Escritos 454 y Matamoro 227-28).
} 
actriz y como escritora, aun habiendo cursado estudios universitarios. Tampoco le permitió divorciarse, lo cual le concedió, a cambio, en palabras de Juan José Sebreli, "pequeñas rebeliones individuales" como el vivir sola, tener amistades masculinas, manejar automóviles o gastar dinero en una revista deficitaria como Sur (Sebreli, Escritos 454). Dentro de su situación de privilegio se atrevió a atacar a la iglesia católica, a la que calificó de "estrecha, limitada, irritante, vacía, hipócrita” (Ocampo, Autobiografía I 114), exhibiendo con bastante valentía su postura. ${ }^{3} \mathrm{Su}$ feminismo además la llevó a polemizar contra la perspectiva machista de Montherlant, Keyserling y Ernesto Sabato. Protestó cuando en 1935 se quiso disminuir en el Código Civil la capacidad jurídica de las mujeres ${ }^{4}$ y apoyó la ley de 1954 de reconocimiento de hijos naturales así como el nacimiento controlado (Sebreli 457-8; Matamoro 267-8).

En cuanto al clima político enrarecido que se respiraba en los años treinta, ${ }^{5}$ década en que se comienza a publicar la revista Sur, Victoria Ocampo primero aceptó dar la conferencia "Supremacía del alma y de la sangre" en Florencia y en Venecia auspiciada por el Instituto Interuniversitario Fascista de Cultura, si bien aclaró en carta privada al gobierno italiano que ella no era fascista. Eso no le impidió dejarse fascinar por el Duce (en Ocampo parece funcionar el "culto del héroe" en la tradición nacionalista fichteana recogida por Carlyle $^{6}$ ) ni ser amante del médico privado de Mussolini y Pío XII, así como tampoco publicar las gratas impresiones que había tenido de su viaje a Italia en 1934 sobre la condición de la mujer en un libro que, tras la invasión a Abisinia y la intervención de Italia en la Guerra Civil Española, no quiso ver reditado. ${ }^{7}$

Tal como recomienda Nietzsche, no es justo aplicar la razón retrospectiva desde un presente en el que los conflictos del pasado parecen simples y superados. El avance del fascismo crea -y surge de- un clima de confusión al que incluso el mismo Mahatma Gandhi, idolatrado por Victoria, sucumbirá al demostrar su simpatía

3 Sin embargo, Ocampo publica y difunde a los católicos conocidos como "personalistas" (Jacques Maritain y Emmanuel Mounier principalmente) que rechazaban tanto el fascismo como el comunismo, el individualismo como el colectivismo (Ver King 81-5).

4 Este proyecto de ley introducido por el presidente Justo pretendía que las mujeres quedaran, como si se tratase de menores de edad, sometidas a la voluntad del marido.

5 Además de la catastrófica caída de la bolsa en Wall Street y de la situación europea, en Argentina se había producido un golpe militar en 1930 por el cual el general José F. Uriburu despojó al país del gobierno democrático de Yrigoyen; es la "hora de la espada" profetizada por el poeta Leopoldo Lugones, ideólogo del golpe a través del diario conservador La Nación. En el país se caracterizó este periodo como "década infame”. Sur comienza a publicarse al año siguiente, en 1931.

6 Asimismo, las obras de Borges y de Bioy Casares tomarán como punto de reflexión el tema del héroe y de lo heroico, y aspectos asociados como la virilidad y el valor. Véase mi artículo "Reformulación de lo heroico borgiano en la obra de Adolfo Bioy Casares”, en Gramma Año XXII, n48, 2011.

7 Se trata de Domingos en Hyde Park, Sur, 1936. 
hacia Mussolini. María Rosa Oliver, amiga de Victoria que más tarde exhibiría una conspicua adhesión al estalinismo, así como el habitual colaborador de Sur Eduardo Mallea, fueron otros tantos intelectuales que en un principio miraron al fascismo con buenos ojos. Sebreli nos recuerda que en una de las publicaciones que Sur tomaba como modelo, la Nouvelle Revue Française, colaboraron fascistas declarados como Pierre Drieu La Rochelle y Louis Ferdinand Céline. ${ }^{8}$ Como sea, sólo a partir del ataque en 1937 de la revista católica nacionalista Criterio, partidaria del fascismo y del franquismo, que acusó a la revista de Ocampo de "izquierdista", Sur traza su distancia del nacionalismo y el fanatismo más reaccionario (Podlubne 64).

Pero las mejores intenciones sociales de Victoria Ocampo no lograron trascender un terreno en el que tanto su pacto con la clase que la había sojuzgado, como su propio talante moralista, o ambas cosas a la vez, le impidieron mostrarse tan magnánima como esa Perséfone de Gide a la que le puso su voz en Argentina y en Europa y con la que no resulta difícil imaginarla identificada. ${ }^{9}$ Aunque muchos de los colaboradores y colaboradoras de Sur no disimulaban sus opciones sexuales, la cuestión gay a Victoria Ocampo nunca le pareció una bandera que hubiera que defender en voz demasiado alta (King 237-8).

No se puede hablar de prejuicio de clase cuando se supone que la clase alta era precisamente uno de los focos de esas actitudes "decadentes" por las que la izquierda podía juzgarla y condenarla. La sofisticación iba de la mano de la permisividad en materia sexual, pero eso no quiere decir que en todo ambiente de clase alta ocurriera de ese modo, ni que todo círculo sofisticado aceptara otra cosa que no fuera el sexo ortodoxo entre hombre y mujer, como lo demuestran las actitudes también homófobas de Breton, Buñuel y Dalí en el seno del surrealismo. En el círculo de Victoria Ocampo se encuentran notoriamente las dos maneras contrapuestas: por un lado su hermana menor Silvina, amiga de Borges y casada con Adolfo Bioy Casares, tuvo una relación cercana con muchos amigos gay que van desde Wilcock y Juan José Hernández hasta Manuel Puig, además de la densa relación epistolar de la propia Silvina con Alejandra Pizarnik, por la que se les atribuyó una relación más íntima de lo que parece haber sido

8 Esto durante la ocupación. El otro modelo de Sur fue la revista inglesa The Criterion, dirigida por T. S. Eliot, escritor de conocida y abierta ideología reaccionaria.

9 En esta obra de Gide, escrita a pedido de Ida Rubinstein y con música de Stravinsky, Perséfone, en lugar de ser raptada por Plutón, elige descender por voluntad propia a los infiernos en un acto libre de solidaridad con los condenados. Recitada por Victoria Ocampo con gran éxito en Buenos Aires y Río de Janeiro en 1936 y en Florencia en 1939 bajo la dirección del propio compositor, se puede interpretar a esta cruza de Perséfone con Victoria como la de una diosa que se sacrifica para el entretenimiento y el cultivo de la clase media de su país. "Ninfas, hermanas mías, dulces compañeras, ¿cómo podría con vosotras, reír y cantar despreocupada, ahora que he visto, ahora que sé que un pueblo insatisfecho sufre y vive en la espera" (Gide 12-13).

$111 \frac{\text { Revista Iberoamericana, Vol. LXXXV, Núm. 268, Julio-Septiembre 2019, } 981-996}{\text { ISSN 0034-9631 (Impreso) }}$ 
en realidad. ${ }^{10}$ Como sea, tanto en las relaciones como en la obra de Silvina Ocampo hay un acercamiento y una insinuación de cierto componente queer que preanuncia la sensibilidad camp que se conformará a partir de los años sesenta. ${ }^{11}$

En cambio, aunque tanto la revista como la editorial Sur publican a notorios autores homosexuales, Victoria protesta contra el tema o lo ignora. Con su venerada Virginia Woolf, así como con Vita Sackville-West y su marido Harold Nicolson, se hizo la disimulada, y a T.E. Lawrence lo justificó por su ascetismo y su espíritu de castigo. De Gide dice que se jacta de su "mala conducta" con "orgullo infantil" (Virginia Woolf en su diario 47) y de la homosexualidad en general, lo siguiente:

Las relaciones homosexuales son siempre, en literatura, objeto de justificaciones grandilocuentes y minuciosas, de reflexiones científicas, o de explicaciones oscuras y torcidas, enturbiadas por un sentimiento de culpa o de debilidad enfermiza que pasa del lamento a la jactancia. El que no se disculpa se elogia a sí mismo, cuando no hace ambas cosas a un tiempo. (338171 T. E. 76)

Asimismo, en carta a María Rosa Oliver a propósito del decorador Jean-Michel Franck:

Terrible. Personas duras, pero no valientes; demasiado débiles para ser eficazmente malos, frívolos y duros. Ásperos y livianos. Sin calor y sin amor, sólo le dan importancia a un bonito cenicero, a un Picasso (lo que ya es mejor), a un vestido de Schiaparelli, a un pañuelo de Edwards \& Butler, a un clip de Cartier, a esas cosas, todo eso en los actuales momentos, resulta indescriptible. (Ocampo citado en Sebreli, Escritos 300)

También se sintió muy molesta cuando en 1948 José Bianco compró los derechos, tradujo y publicó para la revista y más tarde para la editorial Sur Las criadas de Jean Genet. Las quejas del público y la discusión por este tema (que llevó a Victoria a publicar una célebre reseña ${ }^{12}$ ) significaron uno de esos fuertes disensos entre directora y secretario que más tarde llevarían a Bianco a renunciar en 1961. Otro de los motivos, sumado al más visible del famoso viaje de Bianco a Cuba, habría sido la colaboración de Héctor A. Murena en la revista. ${ }^{13}$

10 Ver al respecto Vázquez (134) e Iglesias y Arias (103-5) (utilizamos estos dos libros como "testimonios" más que como documentos, ya que en este último sentido su calidad es demasiado subjetiva y a la larga dudosa) y sobre todo Yvonne Bordelois, Correspondencia Pizarnik (210-12).

11 Puede ser útil consultar las consideraciones de José Amícola sobre Silvina Ocampo y la sensibilidad camp en "La casa de azúcar y el placer de sentirse cruel y ser mujer", en La batalla de los géneros.

12 "Que nos hable de la m... cuanto le dé la gana, si tanto le place, pero que por algún rinconcito deje asomar a la rosa" (Ocampo, "A propósito de Las criadas"17).

13 Leonora Djament, "H. A. Murena: un anómalo en la revista”, ponencia inédita facilitada por la autora. Sigo a Djament en la glosa del artículo de Murena.

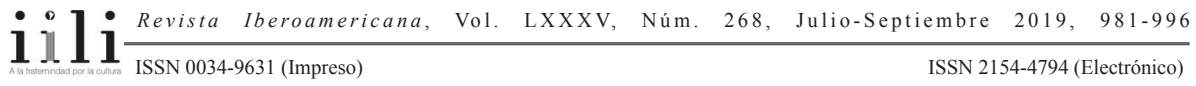


Murena había dado a conocer en 1959 en la revista Sur un artículo sobre la "moda" homosexual titulado "La erótica del espejo", que luego sería recogido en su libro Homo atomicus de 1961, publicado por la editorial Sur. En el mismo número se publicó un cuento de Juan José Hernández (amigo íntimo de Bianco) que aludía al lesbianismo, junto con una colaboración del religioso Thomas Merton, ${ }^{14}$ que se quejó de lo que consideraba una desagradable coincidencia. En el supuestamente apologético artículo de Murena, este discurre de manera un tanto bizantina y caprichosa afirmando que la homosexualidad, aunque turbia, últimamente se había vuelto prestigiosa, que si bien en el plano mental se la rechaza, en el instintivo se la acepta y nadie puede sentirse ajeno a ella: "todos la compartimos de algún modo, pues, al igual que la energía atómica, la dictadura del proletariado, las filosofías existencialistas, etc., la homosexualidad es uno de los factores preponderantes en el zeitgeist en que vivimos" (Murena 21, énfasis en el original). Para Murena la homosexualidad tiene un "carácter demoníaco" y debe condenarse porque, como el comunismo, rechaza la individualidad y propone el resentimiento y el desdén. Sin embargo, pese a todos estos aciagos atributos, hacia el final del artículo Murena da un giro argumentativo inesperado y exhorta a asumir en "nosotros" (un nosotros heterosexual, cabe suponer) la bisexualidad esencial y constitutiva de todo hombre y mujer. Dejando de lado el cuento de Hernández y la "defensa" de Murena, Sur tendió a esquivar el tema, acaso para no tener que lidiar constantemente con quejas como la de Merton. ${ }^{15}$

No demasiado lejos del ámbito de Sur, el costado machista de Borges y en menor medida de Bioy Casares coincide en algún punto con la visión de Victoria Ocampo. Son demasiadas las citas que aparecen en el Borges de Bioy sobre los "maricones", los "putos" y demás epítetos como para consignarlas detalladamente, ${ }^{16}$ aunque algunas resultan harto significativas.

Hablamos de otros posibles candidatos [para la SADE]. BORGES: ¿Quién va a representar a los poetas? ¿Quién va a representar a los judíos? Tarnopolsky. ¿A los

\footnotetext{
14 "Carta a un espectador inocente", donde se dirige de "tú" al lector para demostrar que ser espectador significa necesariamente ser cómplice, pero que por obra de la inocencia podemos desenmascarar a "ellos" (los que buscan el poder sobre los otros). El cuento de Hernández, "El disfraz", se encuentra justo entre el artículo de Murena y el de Merton.

15 Es muy significativo que más tarde en ese mismo año de 1959 se produjera otro escándalo cuando la revista Centro decide publicar en su número 14 el cuento de Carlos Correas "La narración de la historia". El contenido de este texto llevó a un fiscal a iniciar una querella que derivó en el procesamiento del autor, del editor Jorge Lafforgue y del comité editorial, así como en el secuestro del que sería el último número de esta publicación. (Ver José Fraguas y Eduardo Muslip (comps.), Decirlo todo: escritura y negatividad en Carlos Correas. Buenos Aires: Universidad Nacional de General Sarmiento, 2011).

16 Para ello, remito al detallado artículo de Daniel Balderston "El apéndice de Borges: reflexiones sobre el diario de Bioy", inclido en el volumen Innumerables relaciones, y sus observaciones sobre el tema de la homosexualidad entre estos dos autores (155-58).
}

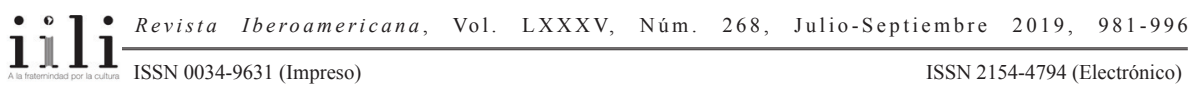


católicos? Dondo. ¿A los putos? ¿Quién? ¿Y al tedium vitae? ¡Rinaldini! ... ¿Y no convendría tal vez intentar una interesante síntesis y llevar un judío que sea puto, de modo de aunar los gremios? (Bioy, Borges, 15 junio 1959, 517)

Es por lo menos llamativa, aunque sea en plan de broma, la equiparación que hace Borges del "judío" con el "puto", dos minorías perseguidas y exterminadas solo un par de décadas atrás. En otra entrada, del 14 de julio de 1968, Bioy rechaza, para la que será su novela Diario de la guerra del cerdo, el título Contra los búhos por temor a que la parodien como Contra los putos (1218). Son exhaustivas y minuciosas las consideraciones sobre la homosexualidad "viril" de Marlowe (26 junio 1957, 297) o sobre un soneto satírico de Quevedo (6 noviembre 1960, 694). Según el padre de Bioy, presencia constante y censuradora en las primeras entradas del diario, Porfirio Barba Jacob es "un maricón imposible" (20 junio 1960, 658). También la madre de Borges es una transmisora de los sentimientos y valores "masculinos" del pasado, aunque sea de la boca para afuera:

-BORGES: En esta semana han muerto dos o tres amigas de Madre, que sintió esas muertes como un presagio: a todas les llevaba entre diez y quince años. No las veía hace tiempo, porque estaban completamente lelas. Para Madre mi viaje fue bastante terrible. Cuando la vi así quise quedarme. Me dijo: "Quiero que vayas". En el momento de la partida yo estaba deshecho; Madre me dijo: "Basta. No seas maricón”. Supe después que se quedó llorando. (30 marzo 1972, 1434)

Virgilio Piñera y un amigo que caen a comer son para Bioy "dos maricas cubanos" (18 junio 1956, 169), apenas se retira Juan Rodolfo Wilcock, Bioy y Borges comienzan a burlarse de él a sus espaldas (25 mayo 1956, 163) ${ }^{17}$ y, como es bien sabido, Witold Gombrowicz es el "conde pederasta y escritorzuelo" (22 julio 1956, 181). Ya en 1991 Daniel Balderston llamó la atención acerca del tratamiento fóbico dado por Borges a un tema que siempre le fascinó. ${ }^{18}$ En cuanto a Bioy Casares, las mujeres lo tenían demasiado ocupado como para detenerse en el tema y además

17 En otra entrada interesante (18 de junio de 1956) comenta Bioy: "Borges comete una gaffe: dice que entre los poemas presentados al concurso de la SADE había uno de Molinari: 'Como los poemas estaban firmados con seudónimo y como el jurado no había sido informado, el poeta pasó inadvertido y premiaron a otro'. La gaffe consiste en que entre los oyentes está Wilcock, que ha pasado inadvertido en otra sección del mismo concurso: el hecho de que Borges no le haya premiado el cuento, rico en palabras como ano y excrementos, y no desprovisto de homosexualidad, da mayor filo a la gaffe."

18 Daniel Balderston, "La 'dialéctica fecal': el pánico homosexual y el origen de la escritura en Borges" en Balderston, incluido en El deseo enorme cicatriz luminosa 61-77. En este artículo, Balderston analiza el grado victoriano de eufemismos a los que Borges recurre para aludir a la homosexualidad de Oscar Wilde y Walt Whitman, así como su representación fóbica de la homosexualidad en "La intrusa" y "La secta del fénix". 
estaba acostumbrado a frecuentar a los amigos de su esposa. ${ }^{19}$

En este ambiente no es de extrañar que encontremos a algunas personalidades ansiosas por ocultar toda posible manifestación o referencia a la homosexualidad. Si por un lado existió la figura exacerbada, de Manuel Mujica Láinez, especie de avatar sudamericano del conde de Montesquieu al que poco o nada le importaba disimular su interés por los muchachos, dentro y fuera de la literatura, y quien hizo de ello algo así como su marca registrada, otros, como José Bianco, optaron por un understatement y unas elipsis dignas de Henry James. Cabe aclarar que Mujica Láinez no perteneció a la redacción de Sur ni al cenáculo de los Bioy, donde lo consideraban ridículo y literariamente amanerado, por lo que vale decir que se habrá visto libre, suponemos, de las censuras inmediatas de sus pares. Bianco, en cambio, se movía entre Victoria Ocampo, Borges y sus padres, Bioy Casares y el doctor Bioy: un ambiente poco propicio para efusiones de intimidad. No obstante, la misma personalidad de Bianco, más allá de las coerciones implícitas del ambiente y de la clase social en que se movía, tiene peso propio en el carácter elusivo, elíptico y enmascarado de sus ficciones. Por eso no es exagerado compararlo con el James más ambiguo de The Spoils of Poynton, donde el autor aclara y oscurece alternativamente la posible atracción lésbica entre una muchacha y su futura suegra. ${ }^{20}$ Bianco, como sus amigos y colaboradores más cercanos, sería de aquellos para quienes ciertas confesiones o determinadas adscripciones resultaban de mal tono, indiscretas cuando no indecorosas. Se sabe que en la intimidad era famoso por sus chismes sobre la alta burguesía con la que alternaba y que aparece reflejada en sus ficciones (Balderston, El deseo 83 y Balderston, Las lecciones), si bien para sus ficciones, precisamente, aplicaba el rasero del buen tono y no se permitía siquiera llegar a donde había llegado su admirado Proust. Como en el siglo XIX inglés, el victorianismo de otra reina, una reina rastacueros según la vio con desdén Virginia Woolf, funcionaba solo en la conciencia de sus súbditos.

\footnotetext{
${ }^{19}$ En ese sentido, Bioy parece haber sido más mundano que Borges, menos aprensivo frente a cualquier manifestación sexual en general. Si bien en un libro juvenil como Caos (1935) la homofobia de Bioy es rampante y claramente defensiva, en los últimos años de su vida, muertas su mujer y su hija Marta, siguió cultivando asiduamente la compañía de una pareja de veterinarios muy amigos de Silvina: Roberto Gerosa y Daniel Tinayre hijo (Iglesias y Arias 156-7) y tras reconocer su paternidad se acercó a su hijo Fabián Ayerza, a quien aceptó con cariño. Por lo demás, las menciones más homófobas tanto de Borges como de Bioy pertenecen a las entradas antiguas del diario, entre 1956 y 1960, luego las alusiones van menguando.

20 A la sazón es la relación que le adjudicaron a Silvina Ocampo con su suegra Marta Casares, y que Sylvia Molloy recrea en clave en su novela El común olvido.
}

$111 \frac{\text { Revista Iberoamericana, Vol. LXXXV, Núm. 268, Julio-Septiembre 2019, } 981-996}{\text { ISSN 0034-9631 (Impreso) }}$ 


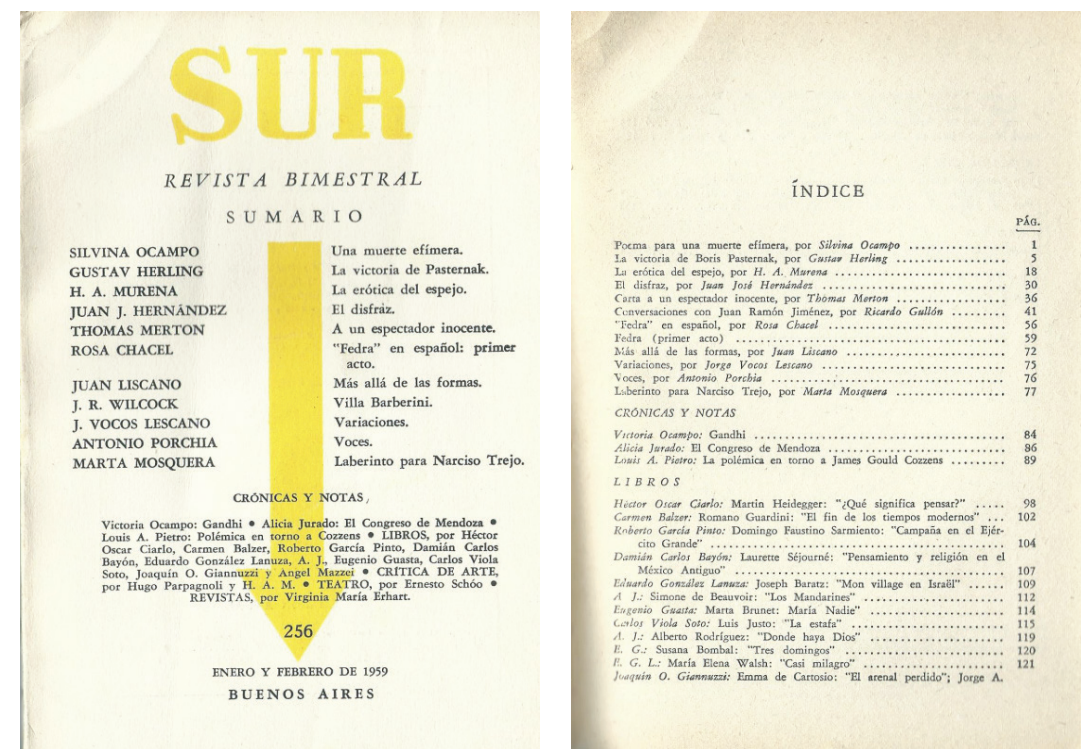

Portada e índice del problemático número 256

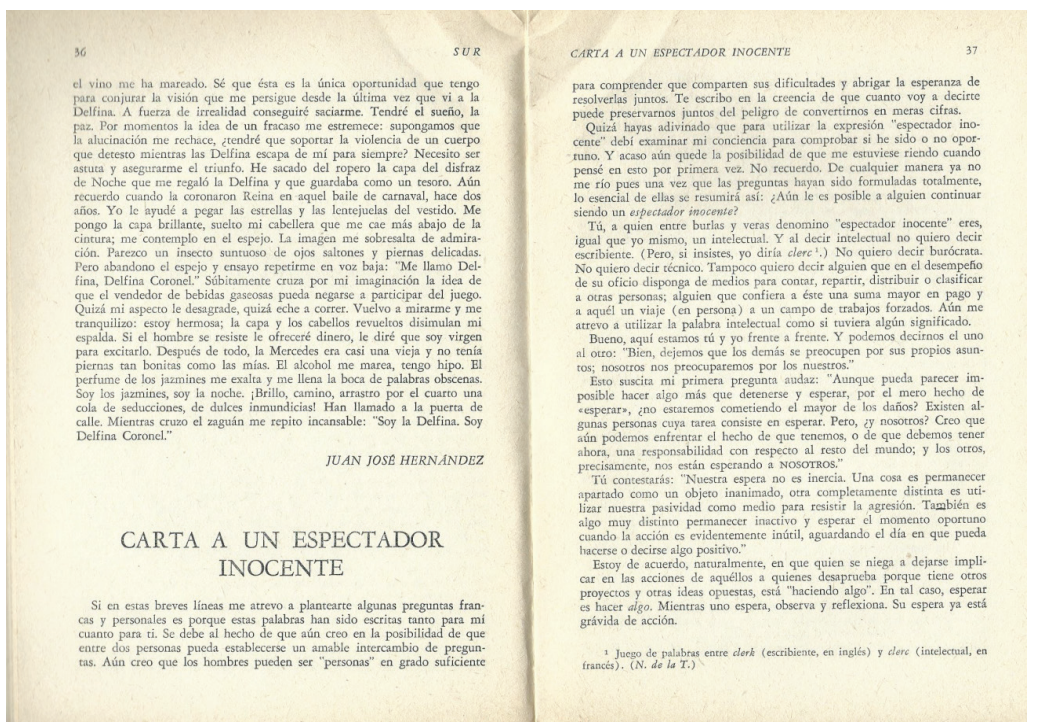

La poco propicia confluencia entre el cuento de Hernández y el artículo de Merton

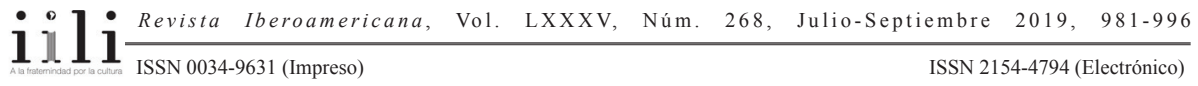


Basta con apenas un detalle para constatar el talante discreto, tímido si se quiere, de alguien poco dispuesto a exponerse a través de sus escritos: de su primer libro de relatos, La pequeña Gyaros, de 1932, Bianco sólo permitió que se reditara el cuento "El límite" corregido por él en 1983. A decir del autor, modificó mayormente aspectos gramaticales que no le convencían, pero también omitió significativamente un epígrafe de un autor tan connotado como Oscar Wilde. En los otros cuentos que no quiso volver a reditar, una mujer cansada de tener amantes se consuela cuando cree haber encontrado un amigo "delicado" ("Tíbulo"), y otra quien piensa abandonar a su marido por una amiga, le ofrece el marido al narrador ("Amarilídeas"). El propio cuento "El límite", en el que la crítica ha visto el núcleo característico de la narrativa de Bianco, trata de un pupilo que utiliza los relatos distorsionados de sus visitas regulares a unas parientas para atraer la atención de un compañero inglés que termina muriendo de un ataque de epilepsia. En este caso se trata de seducir a través de un relato, donde el contenido de ese relato (aquí la prima Bebé ${ }^{21}$ ) actúa al mismo tiempo como interposición. Esta situación constituye lo que junto con Fredric Jameson podríamos llamar "matriz narrativa inconsciente" (unconscious master narrative), por la cual en determinados contextos un topos narrativo podría regresar como fantasma reprimido del discurso. ${ }^{22}$ Esta reiteración presentaría una estructura inestable, a veces incluso contradictoria, aunque conservando una serie de posiciones actanciales y hechos fijos que requerirían la constante repetición, permutación y una continua resolución estructural que siempre será insatisfactoria y que por ello exige nuevos intentos (Jameson 180, Amícola, Autobiografía 238). Si bien el texto de Jameson se refiere a las estrategias inconscientes de quien escribe una autobiografía y no a una ficción en general, esta reflexión teórica se aplica razonablemente bien a esa "escena primigenia" que vuelve una y otra vez (no demasiadas veces ya que la obra de Bianco es breve) en las siguientes ficciones, además de que, como se sabe, su único esfuerzo novelístico es un texto con elementos autobiográficos en clave, novela para muchos fracasada precisamente por su temor a desgraciarse con la clase social a la que hubiera podido describir a la manera de Proust, y seguramente mejor que Victoria Ocampo, quien tampoco lo hizo.

${ }_{21}$ Tanto en "Amarilídeas" como en "El límite" queda, a su vez, sugerida la relación entre dos mujeres (ver Juan Gustavo Cobo Borda, "Una estética del matiz: José Bianco" 256-58).

22 Otra teoría productiva en este caso sería la psicocrítica de Charles Mauron, cuyo método consiste en a) comparar dos o más textos para encontrar repeticiones o agrupamientos de imágenes obsesivas involuntarias; b) ver cómo se modifican y reagrupan las redes o estructuras, que diseñan imágenes o situaciones dramáticas; c) se desemboca en el mito personal y sus avatares, interpretados como expresión de la personalidad inconsciente y su evolución; d) los resultados obtenidos son comparados con la vida del escritor.

$111 \frac{\text { Revista Iberoamericana, Vol. LXXXV, Núm. 268, Julio-Septiembre 2019, } 981-996}{\text { ISSN 0034-9631 (Impreso) }}$ 
Como en "La intrusa" de Borges, pero mucho antes que este cuento, en las narraciones de Bianco hay una donna schermo o mujer-pantalla (en reportajes, Bianco hablará de go-betweens, intermediarios) que es catalizador y obstáculo entre el deseo que dos hombres sienten entre sí y que ni siquiera se atreven a reconocer para sí. Esta mujer-pantalla desvía hacia sí misma las miradas de sospecha puestas en los dos hombres, su función es tapar, disimular. Así, en Las ratas, el narrador Delfín Heredia se identifica con el autorretrato de su padre, que en el presente del relato muestra una imagen idéntica a su hermanastro Julio, hijo bastardo del padre de Delfín. Si bien Delfín asegura que detesta verse en el espejo:

\begin{abstract}
A la noche, irremediablemente, me conducían los gestos, las palabras de Julio. Y yo me asociaba a sus gestos, a sus palabras. Una vez, de sobremesa, mientras Julio retenía una mano de mi madre entre las suyas, me sorprendió como la cara de un desconocido mi propia cara, proyectada sobre los vidrios de una puerta, entre las luces del comedor. Bajé los ojos y observé mis manos deformadas por el estudio, nerviosas, demasiado expresivas, diferentes de las manos de Julio. A partir de entonces mi apariencia física empezó a molestarme como si fuera un disfraz. Poco a poco aprendí a peinarme y pude hacerme correctamente el nudo de la corbata sin ayuda del espejo. Después de todo, yo era el único sitio desde donde podía prescindir de mí mismo, olvidarme. No me miraba jamás. En cambio, desde el piano del vestíbulo, levantaba los ojos, me contemplaba en el retrato. Me contemplaba atentamente, admirativamente. (Las ratas 66)
\end{abstract}

Delfín Heredia repetirá varias veces más el odio que le merece su reflejo y el placer que siente en imaginar que su propia imagen es la del retrato de su padre, "viva imagen" de su hermanastro. Para completar el cuadro, la madre de Delfín mantiene una relación con su hijastro Julio. Delfín se siente atraído por Julio pero cuando logra verlo desnudo, espiándolo en su cuarto oculto tras los armarios en que guarda las ratas con las que trabaja, insiste en su "repugnancia" y poco después le administra el veneno que lo matará. La ambigüedad acusada del texto permite inferir que, en el marco convencional de un drama edípico, Delfín siente celos de la relación entre su madre y Julio, pero en el marco de una relación más complicada en la que la identificación aparece como pantalla del deseo, Delfín en realidad siente celos de Julio por los amores que mantiene con su madre y con Cecilia, la amiga de ésta, pues quiere a Julio para sí.

Pero no resulta fácil llegar a ésta o a cualquier otra conclusión dado el punto de vista engañoso de Delfín como narrador. Refiriéndose a su tía Isabel, dice que "justificaba ... que se ocultaran ciertas cosas cuando no se tiene el valor suficiente para prescindir de ellas" (31) y en un diálogo con Cecilia en que le pregunta si ella insinúa que él miente, Cecilia le responde: "No mientes, pero no dices todo lo que piensas" (48). De esta manera el autor tematiza el motivo del ocultamiento, de la pantalla y de lo "desviado" para poner en alerta al lector.

$111 \frac{\text { Revista Iberoamericana, Vol. LXXXV, Núm. 268, Julio-Septiembre 2019, } 981-996}{\text { ISSN 2154-4794 (Electrónico) }}$ 
También el acaso demasiado largo excurso del capítulo 4 sobre la Sonata en si menor de Liszt que practica Delfín, sugiere la sulfurosa atmósfera romántica del tema del doble y de la pérdida del reflejo. La "hipocresía" de la que al final del texto la madre de Delfín acusa a Julio es la misma que practica el propio Delfín por influjo de su tía Isabel: ella ha remplazado a la inocua profesora de piano por Claudio Núñez, y gracias a eso, Delfín puede interpretar la diabólica partitura. Y si bien Delfín acusa a Cecilia de dejar entrar en la casa un aire decadente con sus canciones de opereta, no menos decadente resulta Claudio Núñez con sus relatos procaces (57). Esta atmósfera general de estancamiento e iniquidad moral es lo que permite comprender el alegórico título, que desde luego no se refiere a las ratas de los experimentos de Julio.

Otra mujer pantalla, la Jacinta Vélez de Sombras suele vestir, aparece entre su hermano autista y su cliente Bernardo Stocker, que afirma que siempre se interpone algo entre él y el muchacho. El texto, en este caso, sugiere que Jacinta no existe, pero ello no impide que sus funciones de interposición y disimulo sean menos eficaces. Por último, en La pérdida del reino, la historia de Rufino Velásquez y Néstor Sagasta aparecerá intermediada por las tres mujeres compartidas.

Además de la fervorosa reseña que escribió Borges sobre Las ratas $^{23}$ es más característico lo que cualquier edición de Bianco repite hasta el hartazgo: las palabras que presentan el volumen Ficción y reflexión, ${ }^{24}$ en donde se lee la conocida -y sibilinafrase: "Como el cristal o como el aire, el estilo de Bianco es invisible", dando a entender que el "estilo" no se interpone entre el relato y el lector. Bianco, como consumado traductor, conocería a fondo la importancia de semejante invisibilidad. Sin embargo, lo que pone de manifiesto con ese estilo "transparente" es justamente el engaño de esa transparencia, cuyo objetivo parece ser el de disimular la calidad de ocultamiento, de disfraz, de pantalla o de membrana, lo "interpuesto", en suma, que constituye la firma de su obra: el triunfo simultáneo de la transparencia y del velo (Starobinski 302). ${ }^{25}$ Gracias al decoro victoriano, compartido en cierta medida con

23 La reseña se tituló "José Bianco: Las ratas".

24 Este texto de Borges apareció originalmente en el diario El país de Madrid el 18 de noviembre de 1983 bajo el título "Página sobre José Bianco", según consta en la bibliografía de Annick Louis para el Borges Center.

25 Así caracteriza Jean Starobinski en su clásico estudio sobre Rousseau. Para el médico y crítico suizo, al mismo tiempo que Jean-Jacques proclama desesperadamente su propia transparencia, se espesa de tinieblas un velo que lo cubre todo. "Rousseau desea la comunicación y la transparencia de los corazones; pero se ve frustrado en su espera y, eligiendo la vía contraria, acepta -y suscita- el obstáculo, que le permite replegarse en la resignación pasiva y en la certeza de su inocencia" (10, traducción mía). Starobinski ha dedicado muchas páginas a dilucidar el tema de la apariencia en las máscaras (tanto en su función de ocultamiento como de revelación) en "La imaginación proyectiva" (La relación crítica); "Ce masque arraché" (Montaigne en mouvement); "Jean-Jacques Rousseau et le péril de la réflexion" y "Stendhal pseudonyme" (L'oeil vivant) entre otros. Ver también: Il soggetto e la maschera de Gianni Vattimo.

$111 \frac{\text { Revista Iberoamericana, Vol. LXXXV, Núm. 268, Julio-Septiembre 2019, } 981-996}{\text { ISSN 0034-9631 (Impreso) }}$ 
Borges, Bianco escribe textos en los que el influjo de lo no dicho, la intensidad de lo sugerido, la morbosidad y la perversión de los rodeos, resultan más expresivos que cualquier afirmación tajante. Pero tal vez ese mismo victorianismo resultó en una autocensura demasiado castradora, en última instancia paralizante. Ya los resultados de La pérdida del reino, con todo lo apasionantes que pueden ser por momentos, resultan en alguna medida frustrantes y no hay que pensar que lo habrán sido menos para el propio autor, quien interrumpió su escritura y la retomó décadas más tarde.

En un comentario crítico a la teoría lévi-straussiana por la cual la mujer es un objeto de intercambio en las relaciones elementales del parentesco, Eve Sedgwick argumenta que también las halagadoras atenciones que recibe la mujer en la poesía romántica son a la vez un desvío y una elaboración del deseo homosocial masculino, en el que las mujeres aparecen como poéticos "objetos de intercambio" al mediar, en su calidad de explícito y ostensible objeto de discurso en la relación de deseo no asumido entre hombres (Sedgwick citado en Butler 203). Es evidentemente cómo la situación aparece plasmada con múltiples recursos y eufemismos en Bianco, donde se alcanzan los rodeos más complicados a través de un sistema de reflejos, desvíos, imágenes sesgadas que constituyen asimismo la propia técnica de su escritura. Tal vez, como dice Balderston (El deseo 81), las archisutiles alusiones de Bianco no hacen más que enardecer el deseo que disfrazan; lo que sí queda claro es que, a diferencia de los poetas románticos de Sedgwick, Bianco sabía de qué deseo estaba hablando, qué deseo estaba disimulando, y la productividad de ese disimulo es la que se plasma en su propia obra. Pero la obra de Bianco es tan escasa que uno duda en considerar "productivo" este modo anal y retentivo del understatement, sobre todo si se lo compara con la producción torrencial de su admirado Henry James.

Si volvemos al mencionado cuento de Juan José Hernández podremos establecer un punto de referencia. El cuento, titulado "El disfraz", se publicó en el mencionado número 256, correspondiente a enero-febrero de 1959, el mismo año que Bianco publica en libro su traducción de la conflictiva obra de Genet, ${ }^{26}$ que guarda algunos puntos en común tanto con Bianco como con Hernández. Ya desde el título, "El disfraz", nos remite al imaginario barroco de máscara, actuación y teatralidad que abunda en la obra de Bianco. Pero aquí la narradora, una costurera jorobada, "nacida bajo el signo de Saturno", ${ }^{27}$ cuenta su pasión no correspondida por su compañera la

${ }^{26}$ Las criadas de Jean Genet fue primero publicada en traducción de José Bianco y Silvina Ocampo en el número 166 de 1948, lo que generó la mencionada crítica de Victoria Ocampo en el número 168. En 1959 aparece en la editorial Sur la traducción solo firmada por José Bianco. Fue gracias a Elena Garro, amiga de Genet, que Bianco entró en conocimiento de este autor (ver el artículo de Lucía Melgar, "Elena Garro en París").

27 Son bien conocidas las relaciones entre melancolía, ironía, alegoría y barroco, tal como se formulan por ejemplo en Origen del Trauerspiel alemán de Walter Benjamin. Aunque la bibliografía sobre el tema es muy abundante, un buen compendio se puede hallar en Jean Starobinski, L'Encre de la mélancolie.

$111 \frac{\text { Revista Iberoamericana, Vol. LXXXV, Núm. 268, Julio-Septiembre 2019, } 981-996}{\text { ISSN 2154-4794 (Electrónico) }}$ 
Delfina Coronel, ${ }^{28}$ una muchacha que abandona su trabajo honesto a la zaga de un empresario de espectáculos dudosos con el que terminará por casarse. La narradora oscila entre el deseo narcisista y el deseo de ser Delfina, como lo resume el final, donde se admira en el espejo luciendo el disfraz que su amiga le regaló tiempo atrás y al que la narradora había ayudado a confeccionar.

Me pongo la capa brillante, suelto mi cabellera que me cae más abajo de la cintura; me contemplo en el espejo. La imagen me sobresalta de admiración. Parezco un insecto suntuoso de ojos saltones y piernas delicadas. Pero abandono el espejo y ensayo repetirme en voz baja: "Me llamo Delfina, Delfina Coronel". (Hernández, "El disfraz" 36)

El esquema de la anécdota es muy similar al de las ficciones de Bianco, una especie de condensación, sólo que mucho más explícita. Por un lado, en el universo de Hernández asoman aspectos grotescos en sus personajes que lo ponen en contacto con el de su amiga Silvina Ocampo pero al que Bianco jamás condesciende; además los personajes pertenecen a la provincia (Tucumán), no a la capital, y son de clase media baja: a diferencia de los burgueses ricos y displicentes de Bianco, los personajes de Hernández se mueven entre fábricas y sindicatos. Por otro lado, y más importante aún, hay un deseo incuestionablemente nombrado. La narradora dice al recibir en su casa a la Delfina: "Miré por el espejo su hermoso cuerpo esbelto y me ruboricé al recordar los entusiasmos que me asaltan por las noches mientras contemplo su fotografía" (33). Como en las soluciones de Bianco, la narradora, atrapada en su narcisismo, jorobada y humillada, identificada con la presunta belleza de la Delfina, al verse abandonada por ella desplaza su deseo a un repartidor de bebidas tosco y poco atractivo, como si así pudiera "actuar" el deseo de la Delfina por los hombres y tal vez, además, como castigo por su propio deseo impuro. Pero a diferencia de Bianco, toda esta estrategia, sin perder nada de su fuerza dramática, queda más manifiesta en Hernández.

Al publicar este cuento de su amigo, Bianco acepta, por preterición, difundir una versión más directa de la que él se atrevió a dar; del mismo modo manifestó oblicuamente su forma de sentir y de pensar a través de la obra de Genet que tradujo. Como en sus ficciones, también aquí Bianco necesita o propone mediadores, gobetweens que sin embargo no lo salvan del castigo de Victoria Ocampo ni de la censura del público. Hay que creer que los tímidos intentos de Bianco por hacer circular tópicos relativos a la homosexualidad fueron tan mal recibidos que calaron

\footnotetext{
28 "Delfina Coronel": el nombre de este personaje sea acaso un eco involuntario de Delfín, el sexualmente ambiguo narrador de Las ratas, y en tal sentido una réplica a dicho relato. En cuanto al apellido, de resonancias viriles evidentes, puede sugerir que la pasión de la narradora no es del todo infundada. La combinación femenina y masculina de nombre y apellido alude quizás aquí al ideal andrógino.
}

$111 \frac{\text { Revista Iberoamericana, Vol. LXXXV, Núm. 268, Julio-Septiembre 2019, } 981-996}{\text { ISSN 2154-4794 (Electrónico) }}$ 
hondo en su sentido estético del decoro, ya que una vez que Bianco se separó de Sur, su uso del understatement sigue siendo el mismo, como queda demostrado por el esquema que repite y que en gran medida desdibuja su mayor esfuerzo narrativo: la novela La pérdida del reino. Al fin y al cabo, y tal vez a su pesar, Bianco no deja de ser el más victoriano de entre los súbditos de Victoria.

\section{BibLIOGRAFÍA}

Amícola, José. Autobiografía como autofiguración. Estrategias discursivas del Yo y cuestiones de género. Rosario: Beatriz Viterbo, 2007.

La batalla de los géneros. Novela gótica versus novela de educación. Rosario: Beatriz Viterbo Editora, 2003.

Balderston, Daniel. Innumerables relaciones: cómo leer con Borges. Santa Fe: Universidad Nacional del Litoral, 2010.

Las lecciones del maestro. Homenaje a José Bianco. Rosario: Beatriz Viterbo, 2006.

El deseo, enorme cicatriz luminosa. Ensayos sobre homosexualidades latinoamericanas. Rosario: Beatriz Viterbo, 2004.

Benjamin, Walter. El origen del Trauerspiel alemán. Madrid: Abada Editores, 2012. Bianco, José . La pequeña Gyaros. [1932]. Buenos Aires: Seix Barral, 1994. Las ratas. Sombras suele vestir. [1941, 1943]. Barcelona: Anagrama, 1987. La pérdida del reino. [1978]. México: FCE, 1990.

Ficción y reflexión. Una antología de sus textos. México: FCE, 1988.

Bioy Casares, Adolfo. Borges. Edición al cuidado de Daniel Martino. Buenos Aires: Destino, 2006.

Caos. Buenos Aires: Viau y Zona, 1934.

Bordelois, Yvonne. Correspondencia Pizarnik. Buenos Aires: Seix Barral, 1998.

Borges, Jorge Luis. “José Bianco: Las ratas". Sur 111 (1944): 76-78.

Butler, Judith. Gender Trouble. Feminism and the Subversion of Identity. [1990]. Nueva York: Routledge, 1999.

Cobo Borda, Juan Gustavo. "Una estética del matiz: José Bianco". Historia crítica de la literatura argentina. T. 9 El oficio se afirma. Sylvia Saítta, dir. Buenos Aires: Emecé, 2004.

Djament, Leonora. "H. A. Murena: un anómalo en la revista", ponencia inédita leída en el Coloquio Internacional "Sur Queer" [2001] organizado por la NYU, Buenos Aires, 18 de noviembre de 2011.

Fraguas, José y Eduardo Muslip (coords.). Decirlo todo: escritura y negatividad en Carlos Correas. Buenos Aires: Universidad Nacional de General Sarmiento, 2011. 
García, Mariano. "Reformulación de lo heroico borgiano en la obra de Adolfo Bioy Casares". Gramma 48 (2011). <https://p3.usal.edu.ar/index.php/gramma/article/ view/789/914>.

Gide, André. Persépone. J. L. Borges, trad. Buenos Aires: Ediciones Revista Sur, 1936.

Gramuglio, María Teresa. "Posiciones de Sur en el espacio literario. Una política de la cultura". Historia crítica de la literatura argentina. Sylvia Saítta, dir. Buenos Aires: Emecé, 2004. 93-122.

Hernández, Juan José. La ciudad de los sueños. Narrativa completa. Buenos Aires; Adriana Hidalgo, 2004.

“El disfraz". Sur 256 (1959): 30-36.

Iglesias, Jovita y Silvia Renée Arias. Los Bioy. Barcelona, Tusquets, 2002.

Jameson, Fredric. The Political Unconscious. Narrative as a Socially Symbolic Act. [1981]. Ithaca: Cornell UP, 1994.

King, John. Sur. Estudio de la revista argentina y de su papel en el desarrollo de una cultura. México: FCE, 1990.

Matamoro, Blas. Oligarquía y literatura. Buenos Aires: Ediciones del Sol, 1975.

Mauron, Charles. Des metaphors obsédantes au mithe personel. París: José Corti, 1963.

Melgar, Lucía. "Elena Garro en París (1947-1952): Una lectura de sus cartas a José Bianco y Ninfa Santos". Elena Garro: Lectura múltiple de una personalidad compleja. Lucía Melgar y Gabriela Mora, comps. Puebla: Benemérita Universidad Autónoma de Puebla, 2002. 1949-72.

Merton, Thomas. "Carta a un espectador inocente". Sur 256 (1959): 36-41.

Murena, Héctor Álvarez. “La erótica del espejo”. Sur 256 (1959): 18-30.

Ocampo, Victoria. 338171 T.E. Buenos Aires, Sur, 1942.

“A propósito de Las criadas". Sur 168 (1948): 12-17.

Autobiografía II. El imperio insular. [1980]. Buenos Aires, Ediciones revista Sur, 1982.

Cartas a Angélica y otros. Eduardo Paz Leston, comp. Buenos Aires: Sudamericana, 1997.

Domingos en Hyde Park. Buenos Aires, Sur, 1936.

Testimonios. Segunda serie 1937-1940. [1941]. Buenos Aires: Sur, 1984.

Testimonios: Sexta serie, 1957-1962. Buenos Aires, Sur, 1963.

Virginia Woolf en su diario. Buenos Aires, Sur. 1954.

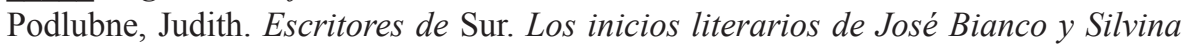
Ocampo. Rosario: Beatriz Viterbo, 2011.

Sebreli, Juan José. Escritos sobre escritos, ciudades bajo ciudades. Buenos Aires: Sudamericana, 1997.

El tiempo de una vida. Autobiografía. Buenos Aires: Sudamericana, 2005.

$111 \frac{\text { Revista Iberoamericana, Vol. LXXXV, Núm. 268, Julio-Septiembre 2019, } 981-996}{\text { ISSN 0034-9631 (Impreso) }}$ 
Starobinski, Jean. Jean-Jacques Rousseau. La transparence et l'obstacle. Paris: Gallimard, 1971.

La relación crítica. Edición revisada y aumentada. Buenos Aires: Nueva Visión, 2008.

L'encre de la mélancolie. París: Ed. Du Seuil, 2012.

Montaigne en mouvement. Edición revisada y aumentada. París: Gallimard, 1993.

Remedio en el mal. Crítica y legitimación del artificio en la era de las luces. Madrid: Antonio Machado, 2000.

Vattimo, Gianni. Il soggetto e la maschera. Nietzsche e il problema de la liberazione. Milán: Bompiani, 1974.

Vázquez, María Esther. La memoria de los días. Mis amigos, los escritores. Buenos Aires: Emecé, 2004.

Willson, Patricia. "Página impar: el lugar del traductor en el auge de la industria cultural". Historia crítica de la literatura argentina. T. 9 El oficio se afirma. Sylvia Saítta, dir. Buenos Aires: Emecé, 2004.

Palabras clave: Revista Sur, fascismo, homosexualidad, mujer-pantalla, ocultamiento/transparecia

Recibido: $\quad 9$ octubre 2015

Aprobado: $\quad 23$ agosto 2016

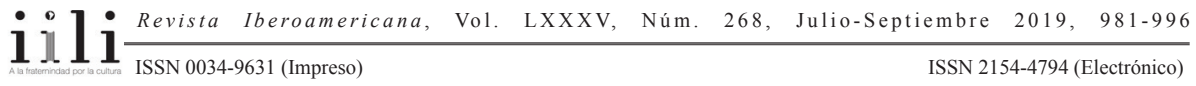

